\title{
Conversion of cellulosic waste materials into nanostructured ceramics and nanocomposites
}

\author{
Suh Cem Pang ${ }^{*}$, Suk Fun Chin, Victor Yih \\ Department of Chemistry, Faculty of Resource Science and Technology, Universiti Malaysia Sarawak, \\ 94300 Kota Samarahan, Sarawak, Malaysia \\ "Corresponding author. Tel: (+6082) 583017; Fax: (+6082) 583160; E-mail: scpang @ frst.unimas.my
}

Received: 3 Jan 2011, Revised: 6 Feb 2011 and Accepted: 14 Feb 2011

\section{ABSTRACT}

Cellulosic waste materials which include sawdust, wastepaper, corncob and sugarcane bagasse were converted into nanostructured ceramics and nanocomposites by submersion in silica colloidal suspension (sol) and subsequently by calcination of the cellulosic/ $\mathrm{SiO}_{2}$ nanocomposites under controlled conditions. Depending on the calcination conditions used, nanostructured $\mathrm{SiO}_{2}$ ceramics and carbon $/ \mathrm{SiO}_{2}$ nanocomposites were obtained. The morphology of resulting nanostructured ceramics and nanocomposites obtained from four types of cellulosic waste materials were characterized by Scanning Electron Microscopy (SEM), Fourier transformed infrared spectroscopy (FTIR), and CHN elemental analyzer. The effect of cellulosic materials on the properties of nanostructured ceramics and nanocomposites formed were investigated. Copyright (C) 2011 VBRI press.

Keywords: Cellulosic materials; nanostructured; ceramics; nanocomposites.

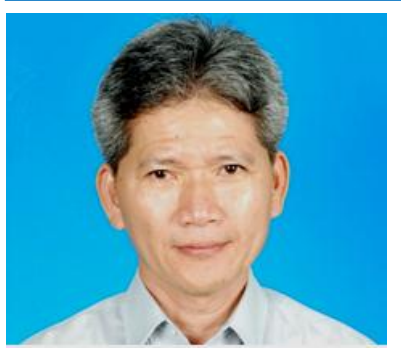

Suh Cem Pang is an Associate Professor at Universiti Malaysia Sarawak (UNIMAS), Malaysia. He obtained his $\mathrm{PhD}$ from the University of Wisconsin-Madison, Wisconsin, USA in 2000. His research interests include synthesis and characterization of nanostructured thin-film materials and starch-based gel electrolytes for electrochemical applications such as thin-film batteries and supercapacitors, as well as biopolymer nanoparticles and hydrogels for controlled and targeted drug delivery

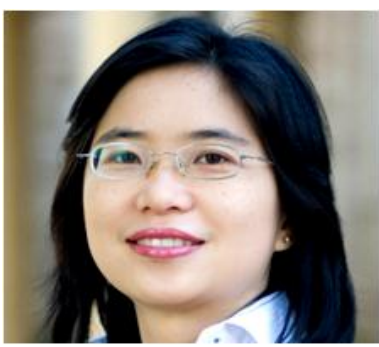
applications.

Suk Fun Chin obtained her $\mathrm{PhD}$ from the University of Western Australia in 2009. Currently, she is a Senior Lecturer at Universiti Malaysia Sarawak (UNIMAS) Malaysia. Her research interests are on synthesis and characterization of magnetic and polymer nanoparticles for biomedical applications

\section{Introduction}

In recent years, the preparation of nanostructured ceramics from biological materials has continued to generate significant interest. Appropriate biological materials have been used as both precursors and templates for the synthesis of hierarchical inorganic materials such as oxides and carbides. Biological materials such as woods possess natural composite structures of high mechanical strength, low density, high stiffness, elasticity and damage tolerances and are therefore suitable to be used as unique nanostructured templates [1]. Some recently published studies have reported the preparation of nanostructured ceramics such as $\mathrm{TiO}_{2^{-}}, \mathrm{Al}_{2} \mathrm{O}_{3^{-}}$and $\mathrm{ZrO}_{2^{-}}$ceramics from the wood-based materials via the sol-gel process with metal-alkoxides [2]. Padel and Padhi used the natural cellulose fibers such as sisal and jute for infiltration with $\mathrm{AlCl}_{3}$ or $\mathrm{TiCl}_{4}$ and subsequent transformation into $\mathrm{Al}_{2} \mathrm{O}_{3}$ or $\mathrm{TiO}_{2}$ fibers by annealing in air $[3,4]$. Ota et al. produced nanostructured $\mathrm{TiO}_{2}$ ceramics by infiltration of wood with titanium tetra-isopropoxide followed by heat treatment in air [5]. Contrary to the traditional ceramic processing technique normally being used for preparing ceramic materials of simple structures, the mineralization of cellulosic materials provides a feasible approach for preparing ceramic materials of complex shapes and microstructures from low cost precursor materials [6].

The present study focused on converting cellulosic waste materials such as sawdust, wastepaper, corncob and sugarcanes bagasse into nanostructured ceramics and nanocomposite materials by impregnating them with silica sol and the subsequent calcinations process under controlled conditions. Such nanostructured ceramics and nanocomposite materials could be utilized for various potential technological applications such as catalyst support, automotive component, armour and light-weight porous ceramics for the aerospace and ground based applications [7]. The economical feasibility and significance of utilizing cellulosic waste materials as renewable and inexpensive sources of carbon and precursor materials are clearly evidenced [8]. Furthermore, these 
cellulosic waste materials could cause environmental problems without any proper waste management. The conversion of cellulosic waste materials into useful nanostructured ceramics and nanocomposite materials therefore provides a very cost-effective ways for reducing landfill wastes.

\section{Experimental}

\section{Cellulosic waste materials}

Four types of cellulosic waste materials were used in this study which include sawdust, sugarcane bagasse, wastepaper and corncob. Sawdust of Kapur wood (Dryobalanops spp) was collected from a local timber sawmill. Waste papers such as printing papers and cartoon boxes were collected from a local university campus. Sugarcane bagasse and corncob were collected from a local market. All cellulosic waste materials were finely grounded to provide high surface area per unit volume for enhanced penetration of silica sol into their cellular structures.

\section{Chemicals}

Among chemicals used in this study include tetraethylorthosilicate (TEOS), ammonia $\left(\mathrm{NH}_{3}\right)$, nitric acid $\left(\mathrm{HNO}_{3}\right)$, hydrogen peroxide $(\mathrm{H} 2 \mathrm{O} 2)$, acetic acid $\left(\mathrm{CH}_{3} \mathrm{COOH}\right)$, hydrochloric acid $(\mathrm{HCl})$, ethanol $(\mathrm{EtOH})$, methanol $\left(\mathrm{CH}_{3} \mathrm{OH}\right)$. All chemicals were used as received without any purification.

Sample Preparation: Wood, corncob and sugarcane bagasse samples

The wood, corncob and sugarcane bagasse samples were cut into smaller pieces and washed thoroughly to remove impurities such as sand and dusts. Samples were then dried at $70{ }^{\circ} \mathrm{C}$ for 24 hours. All cellulosic samples were then grounded into powdery form using a grinder. Lignin in these samples was removed by the leaching process using $1.0 \mathrm{M} \mathrm{HCl}$ at $60{ }^{\circ} \mathrm{C}$ for 24 hours. All samples were washed with ultrapure water and dried at $60^{\circ} \mathrm{C}$ for 24 hours.

\section{Wastepaper sample}

Wastepaper samples such as printing paper and cartoon boxes were being cut into smaller pieces and underwent the initial maceration process to disperse their cellulosic fibers. About $55 \mathrm{~g}$ of wastepaper samples were soaked in a solution mixture of acetic acid and hydrogen peroxide (1:1 $\mathrm{v} / \mathrm{v})$ and placed in a water bath maintained at temperature of $70{ }^{\circ} \mathrm{C}$ for 4 days. The dispersed cellulosic fibers were then separated from the solution mixture by filtration and dried at $70{ }^{\circ} \mathrm{C}$ for 12 hours. The macerated wastepaper fibers were ground into powdery form using a blender. Residual lignin in these samples was removed by leaching with $1.0 \mathrm{M} \mathrm{HCl}$ at $60{ }^{\circ} \mathrm{C}$ for 24 hours.

\section{Preparation of silica $\left(\mathrm{SiO}_{2}\right)$ sol}

The basic silica sol with monodisperse and uniform size of silica nanoparticles was prepared by the hydrolysis of TEOS in ethanol medium in the presence of ammonium hydroxide based on method reported by Rao et al [9]. In a typical synthesis, $10.8 \mathrm{ml}$ of water was first added into 58 $\mathrm{ml}$ of ethanol and stirred for $10 \mathrm{~min}$. $1.6 \mathrm{ml}$ TEOS was then added and again stirred for $20 \mathrm{~min}$. $2.6 \mathrm{ml}$ ammonium hydroxide was added as a catalyst to promote the condensation reaction. The mixture was stirred for 1 hour to obtain a white turbid $\mathrm{SiO}_{2}$ sol or colloidal suspension.

\section{Conversion of cellulosic samples into nanostructured ceramics}

$10 \mathrm{~g}$ of pretreated and ground cellulosic waste materials containing mainly cellulose and hemicellulose were submersed into $50 \mathrm{ml}$ of silica sol in test tubes and continuously shaken for 16 hours. The resulting cellulosic/silica nanocomposites were air-dried at $100{ }^{\circ} \mathrm{C}$ for 3 hours. Nanostructured $\mathrm{SiO}_{2}$ ceramics and carbon/ $/ \mathrm{SiO}_{2}$ nanocomposites were prepared by subsequent heating the cellulosic/silica nanocomposites in air and in nitrogen gas $\left(\mathrm{N}_{2}\right)$, respectively, at $550{ }^{\circ} \mathrm{C}$ for 1 hour and cooled to room temperature at the rate of $5{ }^{\circ} \mathrm{C} / \mathrm{min}$. A flow chart on the conversion of cellulosic samples into nanostructured ceramics and nanocomposites is as shown in Fig. 1.

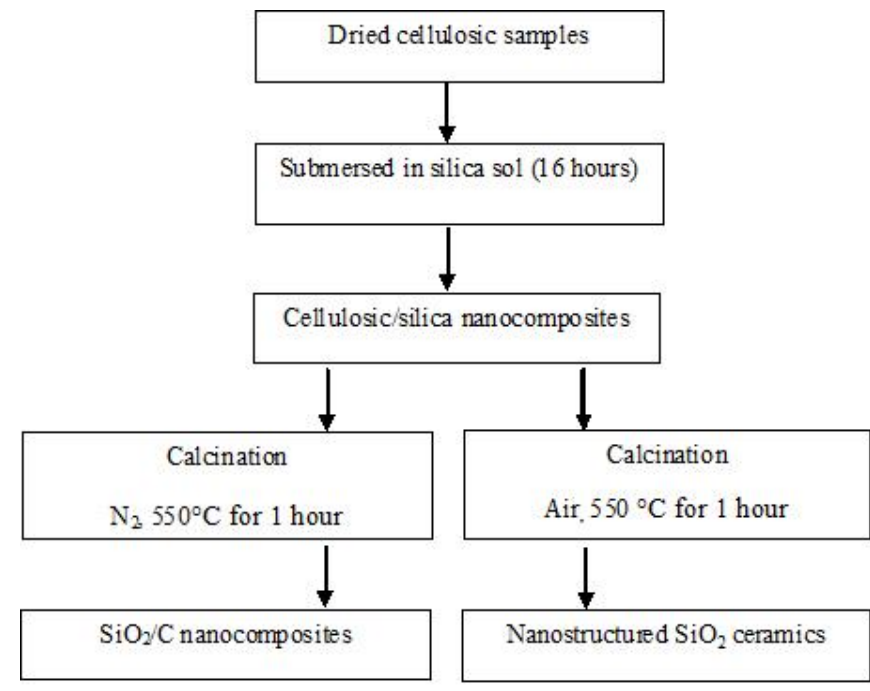

Fig. 1. A flow chart on the conversion of cellulosic samples into nanostructured $\mathrm{SiO}_{2}$ ceramics and $\mathrm{C} / \mathrm{SiO}_{2}$ nanocomposites.

\section{Characterization of nanostructured ceramics and nanocomposites}

Scanning electron microscopy (SEM): All samples were dried overnight, fixed to an aluminum sample stub using double-sided carbon tape and then coated with a thin layer of platinum. These samples were examined by the SEM (JEOL JSM 6400) at an accelerating voltage of $10 \mathrm{kV}$ and equipped with an energy dispersive X-ray spectrometer (EDX)

Fourier transformed infrared spectroscopy (FTIR): FTIR was used to characterize the structure and functional groups that were present in all samples. FTIR spectra were generated from $\mathrm{KBr}$ pellets which were made by mixing homogeneously of $\mathrm{KBr}$ powder and samples in the ratio of 99:1 (w/w) by scanning within the range of 1400-400 $\mathrm{cm}^{-1}$. 
CHN elemental analyzer: Between $2.5 \mathrm{mg}$ to $3.0 \mathrm{mg}$ of sample was placed into an aluminum cup and analysed using a CHN elemental analyzer (Flashea 1112 Series, Thermo Electron Corporation) to determine the percentages of carbon, hydrogen, and nitrogen that were present in each samples.

\section{Results and discussion}

\section{Scanning electron microscopy (SEM)}

Fig. 2 shows the SEM micrographs of cellulosic materials, before and after treated with $1.0 \mathrm{M}$ hydrochloric acid at 60 ${ }^{\circ} \mathrm{C}$ for 24 hours. The surface morphologies of the cellulosic materials were changed substantially after underwent the acid leaching process. As lignin was being removed during the leaching process, the surface morphology of cellulosic materials became rough as the bonding between cellulose fibers had disintegrated. In particular, the surface morphology of sawdust before and after leaching was substantially different due to the removal of lignin and the collapse of cellular structures after acid leaching (Fig. 2 a \& b). Lignin permeates cell walls and the intercellular region which acts as glue and bonds all wood cells to give the hardness of the wood [10]. The removal of lignin caused the cellulose fibers to become loosen and hence the cellular structure of sawdust broke down.

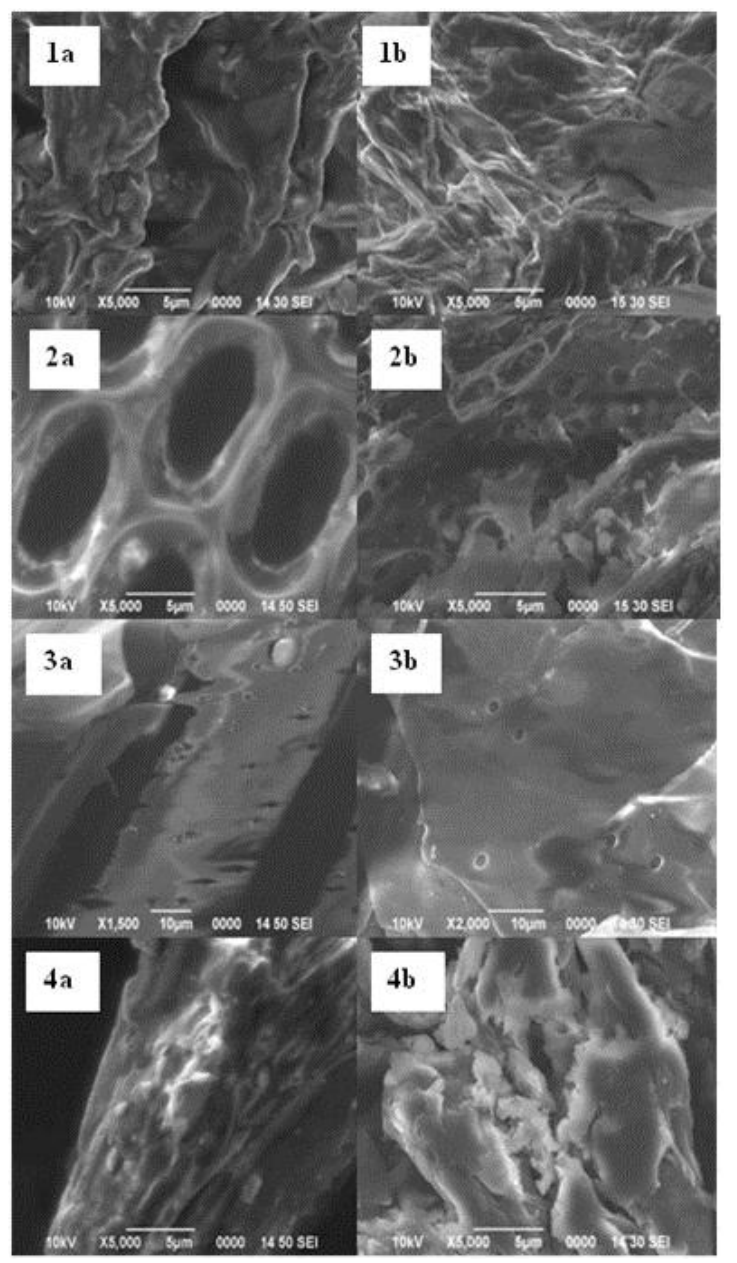

Fig. 2. SEM micrographs of cellulosic materials: (a) before, and (b) after leaching with $1.0 \mathrm{M}$ hydrochloric acid at $60^{\circ} \mathrm{C}$. Cellulosic materials: (1) corncob, (2) sawdust, (3) sugarcane bagasse, and (4) wastepaper.
Cellulosic/ $\mathrm{SiO}_{2}$ nanocomposites were prepared by submersing the cellulosic materials into the silica sol $\left(\mathrm{SiO}_{2}\right)$ at room temperature for 16 hours. Fig. 3 shows SEM micrographs of the cellulosic/ $/ \mathrm{SiO}_{2}$ nanocomposites prepared from various types of cellulosic materials. Silica nanoparticles were observed to have deposited preferentially on the cell wall of cellulosic structures to produce intact cellulosic/ $\mathrm{SiO}_{2}$ nanocomposites which were found to mimic the cellular structures of cellulosic materials. Different types of cellulosic materials would therefore produce cellulosic/ $\mathrm{SiO}_{2}$ nanocomposites with different microstructures and surface morphologies. For the cases of sugarcane bagasse and sawdust samples, silica nanoparticles were only partially coated onto the cellulosic samples, whereas higher coverage of silica nanoparticles was observed on the surfaces of the corncob and wastepaper samples.

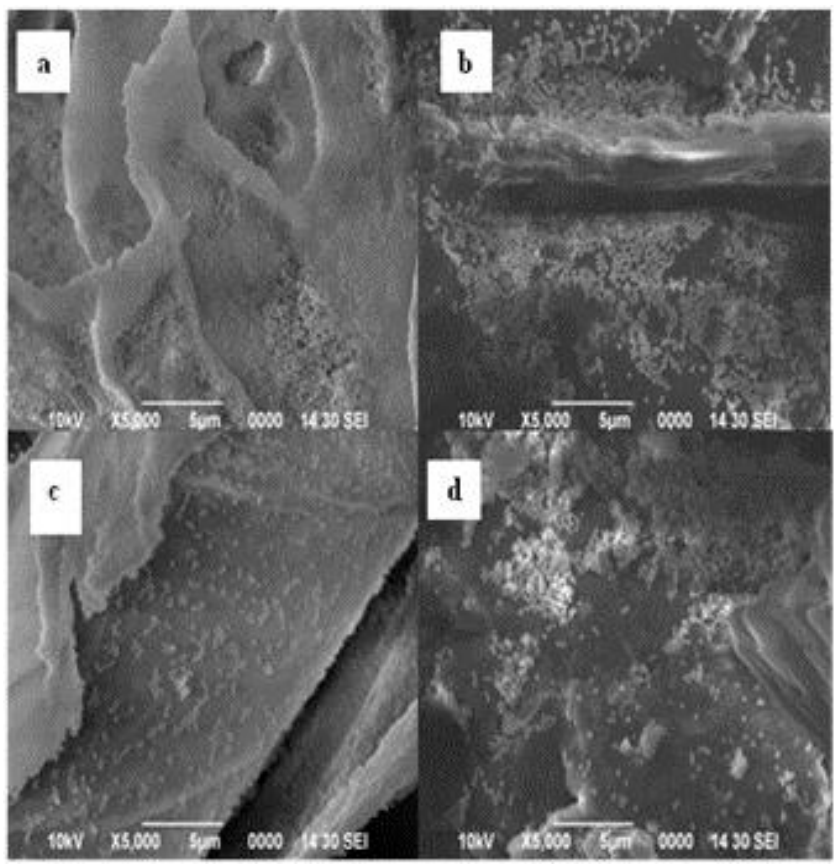

Fig. 3. SEM micrographs of cellulosic materials after treated with silica sol. Cellulosic materials: (a) corncob, (b) sawdust, (c) sugarcane bagasse, and (d) wastepaper.

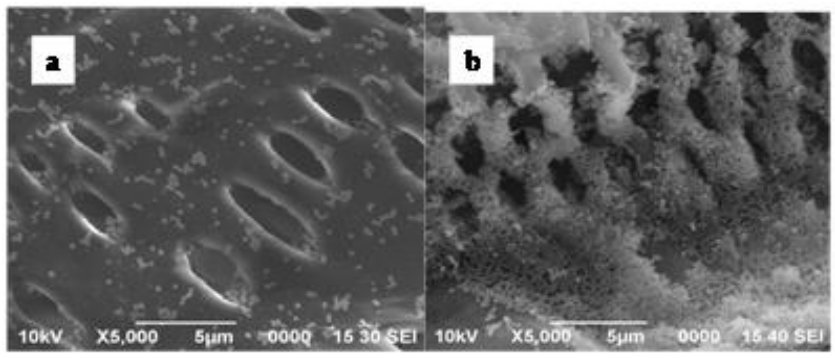

Fig. 4. SEM micrographs of the surface morphology of sugarcane bagasse: (a) before, and (b) after heated in nitrogen at $550{ }^{\circ} \mathrm{C}$ for 1 hour.

Fig. 4 shows the surface morphology of sugarcane bagasse/ $\mathrm{SiO}_{2}$ before and after heat treatment in nitrogen at $550{ }^{\circ} \mathrm{C}$ for 1 hour as observed by SEM. Carbon $/ \mathrm{SiO}_{2}$ nanocomposites were expected to form upon the heat treatment of cellulosic/ $\mathrm{SiO}_{2}$ nanocomposites at $550{ }^{\circ} \mathrm{C}$ in 
nitrogen for 1 hour. The carbon/ $\mathrm{SiO}_{2}$ nanocomposites were observed to mimic the sugarcane bagasse $/ \mathrm{SiO}_{2}$ nanocomposites with the cellular structure of sugarcane bagasse remained intact. Other carbon $/ \mathrm{SiO}_{2}$ nanocomposites were prepared using the same ways from various types of cellulosic/ $\mathrm{SiO}_{2}$ nanocomposites.

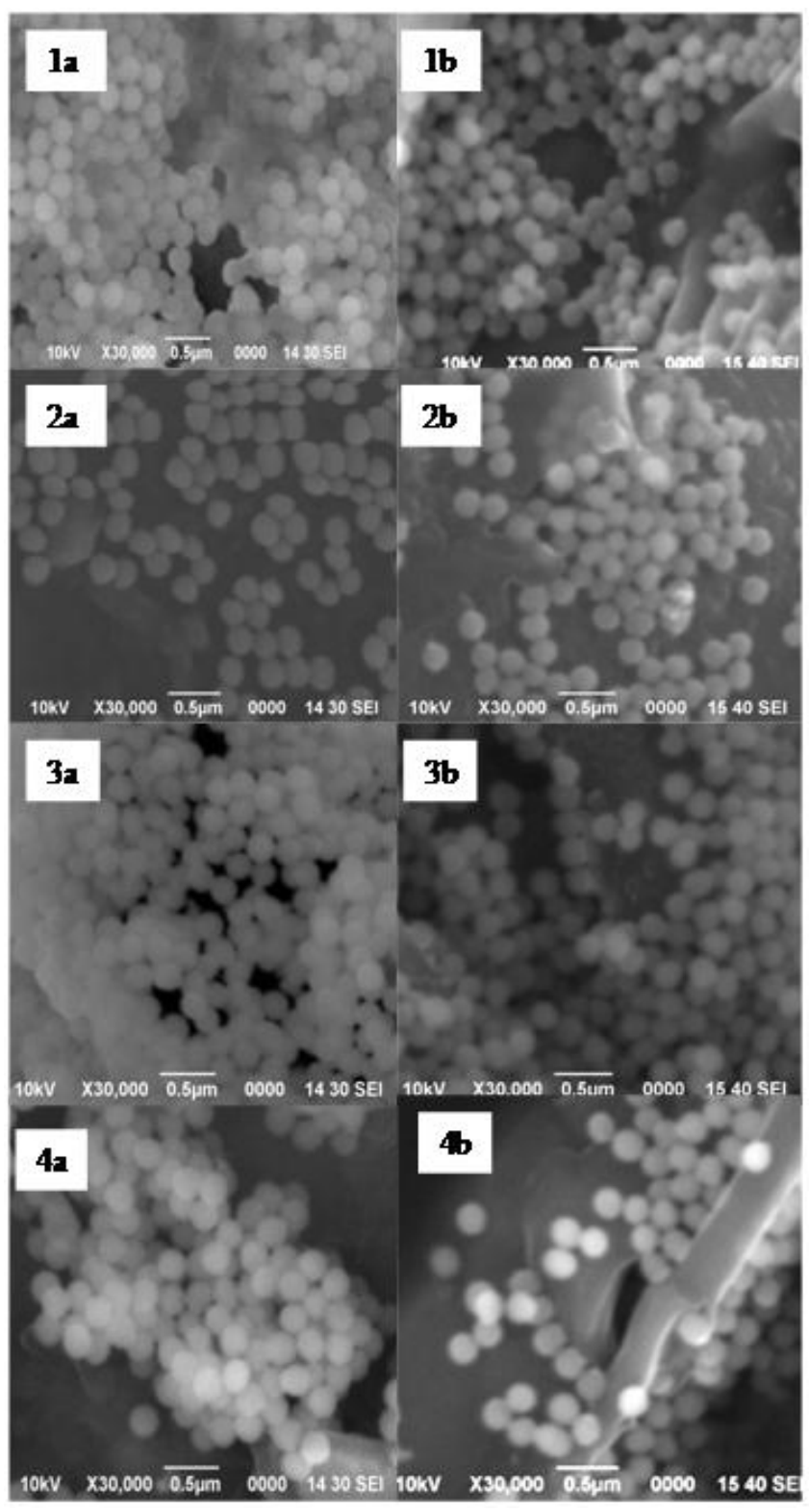

Fig. 5. SEM micrographs of cellulosic/ $/ \mathrm{SiO}_{2}$ nanocomposites after being calcined at $550{ }^{\circ} \mathrm{C}$ for 1 hour in (a) air, and (b) nitrogen. Cellulosic materials: (1) corncob, (2) sawdust, (3) sugarcane bagasse and (4) wastepaper.

Fig. 5 shows the effect of heat treatment on the surface morphology of cellulosic/ $\mathrm{SiO}_{2}$ nanocomposites in air or in nitrogen atmosphere at $550{ }^{\circ} \mathrm{C}$ for 1 hour as observed by SEM. Nanostructured $\mathrm{SiO}_{2}$ ceramics (Fig. 5(a)) and carbon $/ \mathrm{SiO}_{2}$ nanocomposites (Fig. 5(b)) were expected to have formed after being heated in air, and in nitrogen respectively at $550{ }^{\circ} \mathrm{C}$ for 1 hour.

During heat treatment of cellulosic materials in air, the combustion of the entire carbonaceous component of cellulosic materials would occur by reacting with oxygen in the air to form carbon dioxide and water according to equation (1).

$$
\left(\mathrm{C}_{6} \mathrm{H}_{10} \mathrm{O}_{5}\right)_{\mathrm{n}}(s)+6 \mathrm{O}_{2}(g) \rightarrow 6 \mathrm{CO}_{2}(g)+5 \mathrm{H}_{2} \mathrm{O}(l)
$$

Nanostructured $\mathrm{SiO}_{2}$ ceramics obtained from different cellulosic/ $/ \mathrm{SiO}_{2}$ nanocomposites showed different surface morphology. In contrast, the decomposition of cellulosic materials by heating in an inert atmosphere would release volatiles and left behind a carbonaceous compound [11, 12]. The heat treatment of cellulosic/SiO2 nanocomposites in nitrogen would lead to the formation of carbon $/ \mathrm{SiO}_{2}$ nanocomposites with their surface morphologies rather similar to those of cellulosic/ $\mathrm{SiO}_{2}$ nanocomposites.

Table 1 shows the mean particle sizes of nanostructured $\mathrm{SiO} 2$ ceramics that were produced from different types of cellulosic precursor materials. About $100 \quad \mathrm{SiO}_{2}$ nanoparticles were being measured using the field emission scanning electron microscopy software (Smile View version 2.26). The mean diameter of $\mathrm{SiO}_{2}$ nanoparticles was observed to range between 250 and $270 \mathrm{~nm}$. The mean diameter of $\mathrm{SiO}_{2}$ nanoparticles derived from the nanocomposites of corncob/ $\mathrm{SiO}_{2}$ was the largest at $268.6 \pm$ $14.5 \mathrm{~nm}$, as compared to those of sugarcane bagasse (257.3 $\pm 21.6 \mathrm{~nm})$, wastepaper $(255.0 \pm 23.0 \mathrm{~nm})$, and sawdust $(254.0 \pm 21.0 \mathrm{~nm})$.

Table 1. Mean diameter of $\mathrm{SiO}_{2}$ particles in ceramics formed after cellulosic/ $\mathrm{SiO}_{2}$ nanocomposites were heated in air at $550{ }^{\circ} \mathrm{C}$ for 1 hour.

\begin{tabular}{lcc}
\hline \multicolumn{1}{c}{ Sample } & $\begin{array}{l}\text { Mean diameter of } \mathrm{SiO}_{2} \\
\text { nanoparticles in } \mathrm{SiO}_{2} \\
\text { ceramics }(\mathrm{nm})\end{array}$ & $\begin{array}{l}\text { Standard } \\
\text { deviation } \\
( \pm \mathrm{nm})\end{array}$ \\
\hline Silica xerogel & 253 & 20 \\
Corncob & 269 & 14 \\
Sawdust & 254 & 21 \\
Sugarcane bagasse & 257 & 21 \\
Wastepaper & 255 & 23 \\
\hline
\end{tabular}

Fourier transformed infrared spectroscopy (FTIR)

Fig. 6 and 7 show the FTIR spectra of various cellulosic samples before and after the acid leaching process respectively. All FTIR spectra shows similar characteristic absorption peaks of cellulosic materials: a strong and broad peak of $\mathrm{OH}$ stretching $\left(3418-3460 \mathrm{~cm}^{-1}\right)$, a medium intensity absorption peak of CO $\left(1032-1056 \mathrm{~cm}^{-1}\right)$, and a low intensity of $\mathrm{CH}$ methyl group $\left(2902-2930 \mathrm{~cm}^{-1}\right)$ [13]. Fig. 8 shows the FTIR spectra of cellulosic/SiO2 nanocomposites prepared from various types of cellulosic materials. The absorption peak which ranged between 1050 and $1100 \mathrm{~cm}^{-1}$ indicated Si-O-Si stretching due to the presence of silica after these samples were being treated with silica sol [14].

Fig. 9 shows the FTIR spectra of $\mathrm{SiO}_{2}$ xerogel and cellulosic/ $/ \mathrm{SiO}_{2}$ nanocomposites after being calcined in air at $550{ }^{\circ} \mathrm{C}$ for 1 hour. Upon calcination, all carbonaceous components within the cellulosic/ $\mathrm{SiO}_{2}$ nanocomposites would have combusted by reacting with oxygen in the air to form carbon dioxide and water, and the formation of nanostructued $\mathrm{SiO}_{2}$ ceramics. All FTIR spectra of nanostructured $\mathrm{SiO}_{2}$ ceramics showed very similar characteristic absorption peaks as those of $\mathrm{SiO}_{2}$ xerogel (Fig. 9(a)) with very sharp and intense absorption peaks at 
$1090-1110 \mathrm{~cm}^{-1}$ which were attributed to $\mathrm{Si}-\mathrm{O}-\mathrm{Si}$ stretching. Fig. 10 shows FTIR spectra of cellulosic/ $/ \mathrm{SiO}_{2}$ nanocomposites after being calcined in nitrogen at $550{ }^{\circ} \mathrm{C}$ for 1 hour and the expected formation of carbon/ $/ \mathrm{SiO}_{2}$ nanocomposites. These spectra showed sharp and distinct absorption peaks at between $1109-1120 \mathrm{~cm}^{-1}$ indicating the presence of Si-O-Si stretching band [15]. Besides, moderate to decreased intensity of $\mathrm{OH}$ stretching peak as observed at $3418-3460 \mathrm{~cm}^{-1}$ (as compared to the strong and broad $\mathrm{OH}$ peaks of cellulosic/ $\mathrm{SiO}_{2}$ nanocomposites observed in Fig. 8), indicated the carbonization of cellulosic materials and the conversion of cellulosic/ $\mathrm{SiO}_{2}$ to carbon $/ \mathrm{SiO}_{2}$ nanocomposites upon controlled calcination.

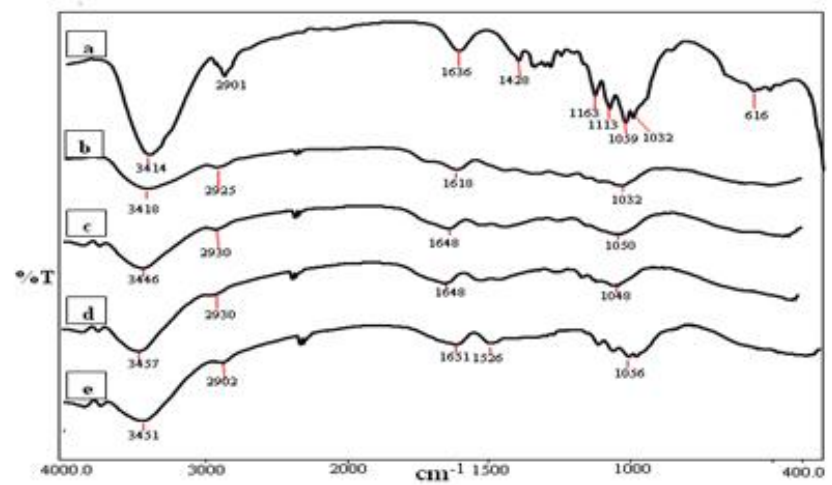

Fig. 6. FTIR spectra of cellulosic materials: (a) Standard pure cellulose, (b) sawdust, (c) corncob, (d) sugarcane bagasse, and (e) wastepaper.

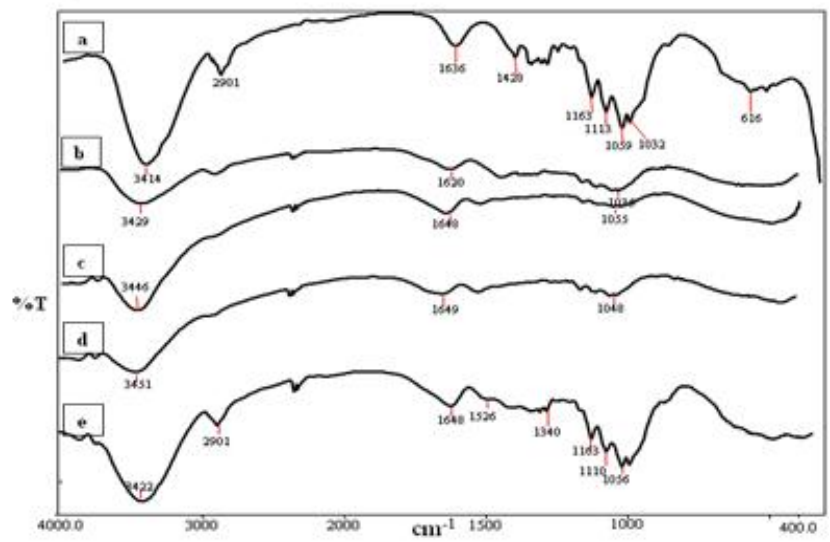

Fig. 7. FTIR spectra of cellulosic materials after acid leaching. Cellulose materials: (a) Standard pure cellulose, (b) sawdust, (c) corncob, (d) sugarcane bagasse, and (e) wastepaper.

\section{CHN elemental analyzer}

The percentage compositions of carbon, hydrogen and nitrogen for various cellulosic materials before and after the acid leaching process were shown in Table 2. The percentage composition of carbon and hydrogen in cellulosic samples was due to various components of cellulosic materials such as hemicelluloses, cellulose and lignin. The presence of trace amount of nitrogen in the corncob could be due to the presence of trace amounts of amino acids. The percentage composition of carbon in the cellulosic materials was observed to decrease slightly after the acid leaching process which could be attributed to the removal of lignin. Generally, all cellulosic materials showed $\mathrm{C}: \mathrm{H}$ molar ratios that were very close to that of pure cellulose $\left(\mathrm{C}_{6} \mathrm{H}_{10} \mathrm{O}_{5}\right)$ n at 6:10.

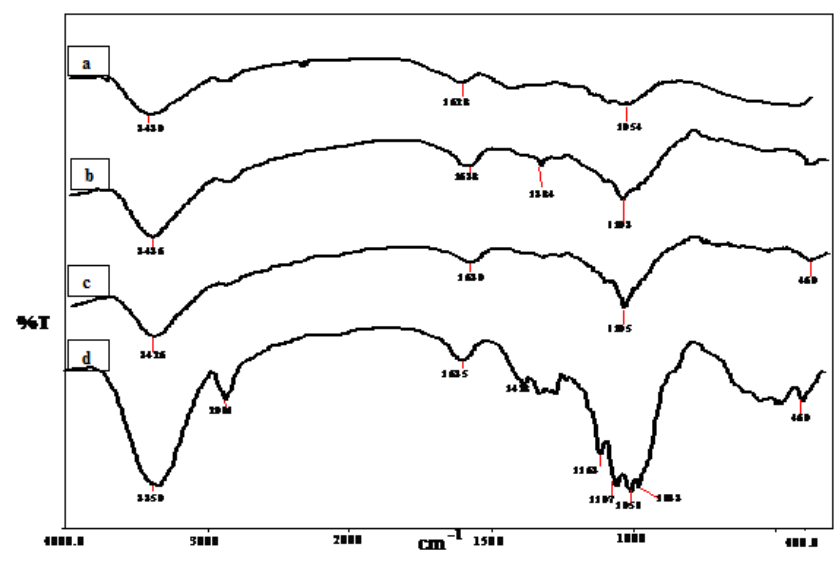

Fig. 8. FTIR spectra of cellulosic/ $/ \mathrm{SiO}_{2}$ nanocomposites. Cellulose materials: (a) sawdust, (b) corncob, (c) sugarcane bagasse, and (d) wastepaper.

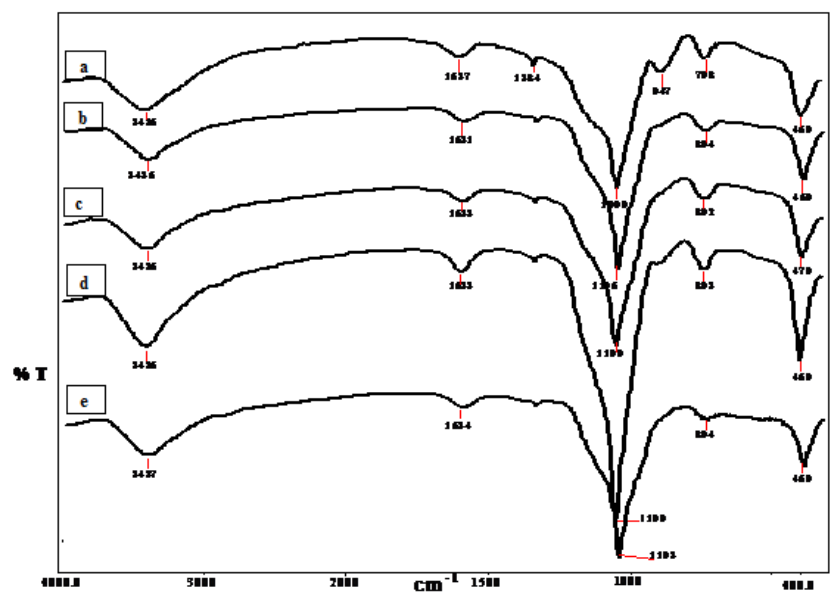

Fig. 9. FTIR spectra of cellulosic/ $/ \mathrm{SiO}_{2}$ nanocomposites after being calcined in air at $550{ }^{\circ} \mathrm{C}$ for 1 hour. Samples: (a) xerogel $\mathrm{SiO}_{2}$ (b) sawdust, (c) corncob, (d) sugarcane bagasse, and (e) wastepaper.

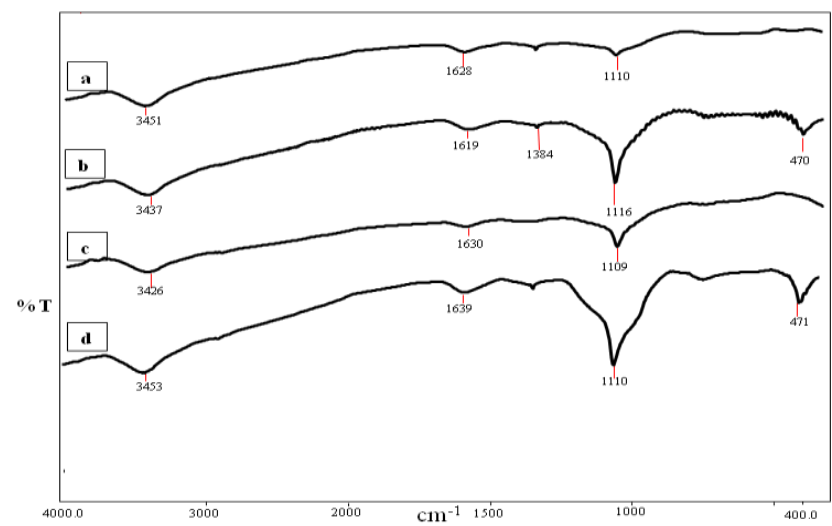

Fig. 10. FTIR spectra of cellulosic/ $\mathrm{SiO}_{2}$ nanocomposites after being calcined in nitrogen at $550{ }^{\circ} \mathrm{C}$ for 1 hour. Cellulosic materials: (a) sawdust, (b) corncob, (c) sugarcane bagasse, and (d) wastepaper.

Table 3 shows the percentage compositions of carbon, and hydrogen in both the cellulosic/ $/ \mathrm{SiO}_{2}$ and carbon/ $/ \mathrm{SiO}_{2}$ 
nanocomposites. The high percentages of hydrogen in the cellulosic/ $\mathrm{SiO}_{2}$ nanocomposites as compared to the carbon $/ \mathrm{SiO}_{2}$ nanocomposites was attributed to the present of various cellulosic components within these samples. In contrast, substantially higher molar ratios of carbon to hydrogen were observed in all carbon $/ \mathrm{SiO}_{2}$ nanocomposites as compared to that of cellulosic/ $\mathrm{SiO}_{2}$ nanocomposites. The carbonization of cellulose, hemicelluloses and residual lignin which were initially present within the cellulosic/ $\mathrm{SiO}_{2}$ nanocomposites upon calcination in inert atmosphere at $550{ }^{\circ} \mathrm{C}$ gave rise to the observed increased carbon to hydrogen ratios in all carbon $/ \mathrm{SiO}_{2}$ nanocomposites. However, the presence of small amount of hydrogen within the carbon/ $\mathrm{SiO}_{2}$ nanocomposites could be attributed to incomplete carbonization of the cellulosic components during the calcination process.

Table 2. Percentages and molar ratios of carbon: hydrogen in various cellulosic materials, (a) before and (b) after acid leaching process.

\begin{tabular}{llllll}
\hline $\begin{array}{l}\text { Cellulosic } \\
\text { materials }\end{array}$ & $\begin{array}{l}\text { Weight of sample } \\
(\mathrm{mg})\end{array}$ & $\begin{array}{l}\text { Carbon } \\
(\%)\end{array}$ & $\begin{array}{l}\text { Hydrogen } \\
(\%)\end{array}$ & $\begin{array}{l}\text { Nitrogen } \\
(\%)\end{array}$ & $\begin{array}{l}\text { C:H molar } \\
\text { ratio }\end{array}$ \\
\hline Corncob & 2.937 & 42.504 & 6.456 & 0.334 & $6: 10.9$ \\
Sawdust & 2.570 & 48.599 & 5.968 & 0 & $6: 8.8$ \\
Sugarcane bagasse & 2.753 & 44.412 & 6.080 & 0 & $6: 9.8$ \\
Wastepaper & 2.672 & 39.053 & 5.964 & 0 & $6: 10.9$ \\
\hline
\end{tabular}

Table 3. Percentages and molar ratios of carbon: hydrogen in: (a) cellulosic/ $\mathrm{SiO}_{2}$ and (b) carbon $/ \mathrm{SiO}_{2}$ nanocomposites.

\begin{tabular}{|c|c|c|c|c|c|}
\hline $\begin{array}{l}\text { (a) Cellulosic } \\
\text { materials }\end{array}$ & $\begin{array}{l}\text { Weight of } \\
\text { sample (mg) }\end{array}$ & $\begin{array}{l}\text { Carbon } \\
(\%)\end{array}$ & $\begin{array}{l}\text { Hydrogen } \\
(\%)\end{array}$ & $\begin{array}{l}\text { Nitrogen } \\
(\%)\end{array}$ & $\begin{array}{l}\mathrm{C}: \mathrm{H} \text { molar } \\
\text { ratio }\end{array}$ \\
\hline Corncob & 2.846 & 42.271 & 6.406 & 0.120 & $6: 10.9$ \\
\hline Sawdust & 2.949 & 44.118 & 5.985 & 0 & $6: 9.8$ \\
\hline $\begin{array}{l}\text { Sugarcane } \\
\text { bagasse }\end{array}$ & 2.920 & 41.979 & 6.082 & 0 & $6: 10.3$ \\
\hline Wastepaper & 2.617 & 37.594 & 6.034 & 0 & $6: 11.5$ \\
\hline o) $\begin{array}{l}\text { Cellulosic } \\
\text { materials }\end{array}$ & $\begin{array}{l}\text { Weight of sample } \\
\text { (mg) }\end{array}$ & $\begin{array}{l}\text { Carbon } \\
(\%)\end{array}$ & $\begin{array}{l}\text { Hydrogen } \\
(\%)\end{array}$ & $\begin{array}{l}\text { Nitrogen } \\
(\%)\end{array}$ & $\mathrm{C}: \mathrm{H}$ molar ratio \\
\hline Corncob & 2.926 & 41.295 & 5.582 & 0.380 & $6: 9.8$ \\
\hline Sawdust & 2.666 & 47.811 & 6.217 & 0 & $6: 9.4$ \\
\hline $\begin{array}{l}\text { Sugarcane } \\
\text { bagasse }\end{array}$ & 2.967 & 39.957 & 5.504 & 0 & $6: 10$ \\
\hline Wastepaper & 2.841 & 43.874 & 5.991 & 0 & $6: 9.8$ \\
\hline
\end{tabular}

\section{Conclusion}

This study demonstrated the successful conversion of cellulosic waste materials into nanostructured $\mathrm{SiO}_{2}$ ceramics and carbon $/ \mathrm{SiO}_{2}$ nanocomposites. The nanostructured $\mathrm{SiO}_{2}$ ceramics and carbon $/ \mathrm{SiO}_{2}$ nanocomposites were prepared by submersing cellulosic materials into silica sol and followed by calcination at 550 ${ }^{\circ} \mathrm{C}$ in air and nitrogen, respectively. SEM micrographs showed the presence of silica nanoparticles within the cellular structure of cellulosic/ $\mathrm{SiO}_{2}$ nanocomposite materials. Depending on the microcellular architecture of the initial cellulosic materials, both the carbon $/ \mathrm{SiO}_{2}$ and cellulosic/ $\mathrm{SiO}_{2}$ nanocomposites would mimic these microcellular structures. As such, nanostructured $\mathrm{SiO}_{2}$ ceramics that were produced should exhibit defined and specific microstructure depending on the types of cellulosic materials used. The submersion of cellulosic materials into silica sol and the subsequent calcinations process under controlled conditions have provided a very versatile and cost effective synthesis approach for the preparation of nanostructured ceramics and nanocomposites. Besides, the availability of unique microstructures in natural biological materials has made this fabrication approach very promising for the preparation of nanostructured $\mathrm{SiO}_{2}$ ceramics and carbon $/ \mathrm{SiO}_{2}$ nanocomposites of tailored microstructure and complex shapes. The potential utility of these nanostructured ceramics and nanocomposite materials for various technological applications is envisaged.

\section{Acknowledgement}

This work was supported in part by the Universiti Malaysia Sarawak under the special fundamental research grant 01(K03)/557/2005(56).

\section{References}

1. Yan, T.; Wei, D.; Zheng, X.; Xin, X.; Zhang, N.; Wu, D.; Yan, L.; Li, H.; Du, B.; Wei, Q. Adv Mat Lett. 2010, 1, 106. DOI: 10.5185 /amlett.2010.4111

2. Mamoru, M.; Haruyuki, T.; Nobuyasu, A.; Toshitaka, O.; Keiji, D.; Yasuo, H.; Sci. Technol. dv. Mater. 2005, 6, 76.

DOI: $10.1016 /$ j.stam.2004.08.004

3. Patel, M.; Padhi, B.K. J. Mater. Sci. Lett. 1993, 12, 1234. DOI: $10.1007 / \mathrm{BF} 00274510$

4. Cao, J.; Rambo, C.R.; and Sieber, H. J. Porous Mater. 2004, 11, 163.

DOI: $10.1023 / \mathrm{B}: J O P O .0000038012 .58705 . \mathrm{c} 9$

5. Ota, T.; Imaeda, M.; Takase, H.; Kobayashi, M.; Kinoshita, N.; Hirashita, T.; Miyazaki, H.; Hikichi, Y. J. Am. Ceram. Soc. 2000, $83,1521$.

DOI: $10.1111 / \mathrm{j} .1151-2916.2000 . t b 01421 . \mathrm{x}$

6. Singh, M.; Yee, B.M. J. Am. Ceram. Soc. 2002, 23, 719. DOI: $10.1002 / 9780470294758 . \operatorname{ch} 80$

7. Singh, V.; Singh, S.K.; Pandey, S.; Sanghi, R. Adv Mat Lett. 2010, 1,40 . DOI: $10.5185 /$ amlett.2010.4107

8. Chauhan, V.S.; Yunus, M.; Sankararamakrishnan, N. Adv Mat Lett. 2010, $1,225$.

DOI: $10.5185 /$ amlett.2010.6135

9. Rao, K.S.; Khalil, E.H.; Kodaki, T.; Matsushige, K.; and Makino, K. J. Colloid Interface Sci. 2005, 289, 125. DOI: $10.1016 /$ j.jcis.2005.02.019

10. Egelja, A.; Gulicovski, J. A. Devecerski, B; Babic, M; Miljkovic, S; Boskovic, B; Matovic, J. Serb. Chem. Soc. 2008, 73, 745. DOI: $10.2298 / \mathrm{JSC} 0807745 \mathrm{E}$

11. Shin, Y.; Gregory, J.E. Cellulose, 2007, 14, 269. DOI: $10.1007 / \mathrm{s} 10570-006-9101-0$

12. Shin, Y.; Wang, C.M.; Exarhos, G.J. Adv Mater. 2005, 17, 73. DOI: 10.1002 /adma.200400155

13. Colom, X.; Carrilo, F; Nagues, F.; Garriga, P. Poly. Degrad. Stab. 2003, 80, 543.

DOI: $10.1016 / \mathrm{S} 0141-3910(03) 00051-\mathrm{X}$

14. Dumas, R.L.; Tejedor-Tejedor, I.; Anderson, M.A. J. Porous Mater. 1998, 5,95 . DOI: $10.1023 / \mathrm{A}: 1009682117946$

15. Duran, A.; Serna,C.; Fornes, V.; Fernandez Navarro, J.M. J. NonCryst. Solids. 1986, 82, 69.

DOI: $\underline{10.1016 / 0022-3093(86) 90112-2}$ 


\section{AdVANCED MAterials Letters}

\section{Publish your article in this journal}

ADVANCED MATERIALS Letters is an international journal published quarterly. The journal is intended to provide top-quality peer-reviewed research papers in the fascinating field of materials science particularly in the area of structure, synthesis and processing, characterization, advanced-state properties, and applications of materials. All articles are indexed on various databases including DOAJ and are available for download for free. The manuscript management system is completely electronic and has fast and fair peer-review process. The journal includes review articles, research articles, notes, letter to editor and short communications.

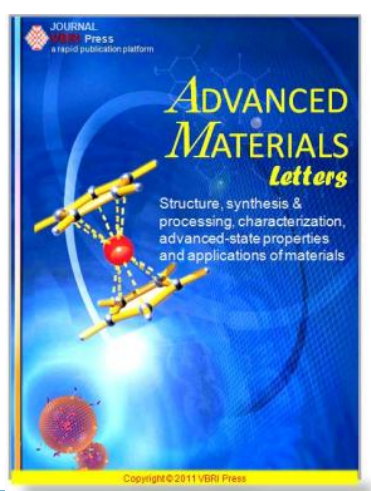

